\title{
FATORES (IN)CONSCIENTES QUE INFLUENCIARAM UMA ÍTALO- BRASILEIRA A USAR PROGRESSIVAMENTE O PORTUGUÊS EM DETRIMENTO DA VARIEDADE ITALIANA
}

\author{
(UN)CONSCIOUS FACTORS THAT INFLUENCED AN ITALIAN-BRAZILIAN WOMAN \\ TO USE PROGRESSIVELY MORE PORTUGUESE THAN ITALIAN
}

\author{
Cristiane Horst ${ }^{95}$ \\ Marcelo Jacó Krug ${ }^{96}$ \\ Simone Raquel Bernieri ${ }^{97}$
}

\begin{abstract}
RESUMO: Com o presente artigo buscou-se compreender os fatores (in)conscientes que influenciaram a decisão de uma italo-brasileira com hoje 90 anos, cuja língua materna foi uma variedade italiana, a usar progressivamente, com mais dominância, o português em detrimento de sua primeira língua. Investigou-se de que forma a língua instituída como língua nacional, no caso o português, foi gradualmente ganhando mais espaço e dominância na vida da informante desta pesquisa. A metodologia utilizada foi gravação audiovisual da aplicação de questionário (meta)linguístico (KRUG, 2013) e análise dos dados. As motivações para que aprendesse uma nova língua foram distintas em cada período de sua vida: primeiramente foi o medo da punição empregada aos que não falassem o português no Brasil na década de 30, durante o Estado Novo, levando-a a usar português em contatos sociais e a variedade italiana no seio familiar. Além disso, havia o receio em ofender os que eram apenas falantes de português ao usar a variedade minoritária. Posteriormente, com o nascimento dos filhos, a motivação em usar o português surgiu da preocupação de que estes tivessem uma vida escolar bem-sucedida, e para isso a variedade de imigração italiana não poderia "atrapalhar" o desenvolvimento das habilidades com o português. Com o nascimento dos netos, a preocupação foi de estreitar laços afetivos, aproximando-se deles com o uso da língua que compreendiam, passando assim, com a chegada dos netos, a usar o português com maior dominância.
\end{abstract}

Palavras-chave: Bilinguismo; Fatores de substituição linguística; Língua de imigração italiana; Português.

ABSTRACT: Throughout this article we aim to understand the (un)conscious factors that influenced the decision of a 90-year-old Italian descendant woman, whose mother tongue was one variety of Italian, speaking progressively more Portuguese than her mother tongue. We aim to investigate why the Brazilian national language progressively reached more dominance of usage. The methodology for the research was audiovisual record of an interview done by asking a meta-linguistic questionnaire (KRUG, 2013) and the analysis from the answers obtained. The motives that made her learn another language were different in every moment of her life. Firstly it was the fear of the punishment suffered by those who didn't speak Portuguese in Brazil in the 30's, making her use her native language at home and Portuguese in external social contexts. Then, when her children were born, it was the concern about their progress in the studies, because if they spoke the minority language they were punished at school, and the school success would depend on their perfect proficiency in Portuguese. So, it made her start using both languages at home. Later, it was when her grandchildren who didn't understand another language besides Portuguese were born, the motivation for using just Portuguese at home was to promote affective bonds with them.

Keywords: Bilingualism; Language substitution factors; Italian immigration language; Portuguese.

\section{Introdução}

O panorama linguístico do Brasil é de multilinguismo. A imagem da unidade da língua nacional brasileira propiciou de certa forma uma imagem distorcida de nossa identidade

\footnotetext{
${ }^{95}$ Doutora em Letras/Filologia Românica pela Christian-Albrechts-Universität zu Kiel (Alemanha). Professora associada I da Universidade Federal da Fronteira Sul - Campus Chapecó - UFFS. Pesquisadora e docente do Mestrado em Estudos Linguísticos - PPGEL.

${ }^{96}$ Doutor em Letras/Filologia Românica pela Christian-Albrechts-Universität zu Kiel (Alemanha). Professor associado I na Universidade Federal da Fronteira Sul - Campus Chapecó - UFFS. Pesquisador e docente do Mestrado em Estudos Linguísticos - PPGEL.

${ }^{97}$ Mestrado em Estudos Linguísticos pela Universidade Federal da Fronteira Sul-UFFS.
} 
linguística, remetendo à ilusão de que somos um país monolíngue, dominado pelo português em toda sua extensão, fato que camufla nossa realidade plurilíngue, marcada pela coexistência de várias línguas além do português. De acordo com Ferraz (2007, p. 43) "a realidade multilingual em um mesmo território nacional tem sido um fato a permitir amplas análises no que concerne ao contato de línguas, com suas implicações na esfera das questões socioculturais.”

O multilinguismo no Brasil é constituído pela existência de uma língua oficial, de maior prestígio social (português) e de línguas minoritárias, que são as faladas por um grupo de pessoas em um país cuja língua oficial é diferente. Atualmente, a estimativa de número de línguas presentes em território nacional é apresentada, por diferentes pesquisadores, com dados que oscilam: Segundo Oliveira (2008, p. 3) "No Brasil hoje são faladas por volta de 210 línguas. As nações indígenas do país falam cerca de 170 línguas (chamadas autóctones), as comunidades de descendentes de imigrantes cerca de 30 línguas." Para Altenhofen (2013) a estimativa é de que haja no Brasil 330 línguas, total constituído de 274 línguas autóctones, 56 variedades alóctones.

Línguas autóctones são línguas de grupos indígenas, as primeiras presentes em solo brasileiro. Línguas alóctones são as línguas de imigração, definidas por Altenhofen e Margotti (2011, p. 290) como:

1) originárias de fora do país (alóctones) que, no novo meio, compartilham o status de língua minoritária. Distinguem-se das línguas indígenas (autóctones) e de línguas específicas (como as línguas de sinais), que, embora também constituam línguas minoritárias, não possuem na sua gênese um processo de imigração.

Considerando-se que quando os portugueses chegaram ao Brasil nossa nação era povoada por indígenas, é interessante pensarmos que o português também pode ser considerada uma língua de imigração, que foi promovida a língua nacional. É possível percebermos o poder da instituição desta língua quando, segundo Ferraz (2007 p. 46), considerarmos que:

Antes do início da colonização pelos europeus, a diversidade das línguas existentes no Brasil refletia-se em um número de aproximadamente 1200 línguas faladas por diversos povos indígenas, segundo dados levantados por Rodrigues (1993), o que significa que apenas $15 \%$ teriam sobrevivido.

Dentre as línguas de imigração, encontramos as de imigrantes africanos que foram forçados a virem ao Brasil ao longo de três séculos através do tráfico de escravos, e línguas de asiáticos e europeus que após a abolição da escravatura, em finais do século XIX e início do século XX, o Brasil recebeu em grande fluxo, em uma campanha imigratória que buscava mão de obra para o desenvolvimento do país, favorecendo e impulsionando a contratação destes imigrantes.

O sul de nosso país é marcado pela formação de colônias de imigrantes europeus, dentre elas, a de italianos, que primeiramente instalaram-se no Rio Grande do Sul e depois migraram para Santa Catarina em busca de novas terras férteis. Segundo Vicenzi (2008, p. 16):

A colonização europeia no Sul do Brasil por pequenos proprietários camponeses ensejou a formação de núcleos coloniais pioneiros - Colônias Velhas - que gradativamente expandiam-se através da chegada de novos imigrantes e sobretudo do aumento demográfico vegetativo que produziu uma população à procura de terras virgens e férteis para formar novos núcleos-Colônias Velhas. Nesse processo, principalmente imigrantes casados adquiriam uma colônia, para explorá-la, nas terras postas à disposição pelo Estado ou empresas particulares. A chegada dos filhos aumentava a força de trabalho e, portanto, a produção. Ao crescerem e se casarem, os filhos buscavam um novo lote, onde fosse possível prosseguir com o ciclo iniciado 
pelos pais [...]. Com o esgotamento das terras à disposição da migração no Rio Grande do Sul, a frente de expansão colonial agrícola sul-rio-grandense atravessou o Rio Uruguai para instalar-se e Santa Catarina.

Muitos colonos riograndenses migraram para o noroeste do estado de Santa Catarina - que naquele período compreendia o município de Chapecó - em busca de terras férteis. Neste processo de formação de colônias, o elo em comum das novas comunidades em formação era o anseio de uma vida próspera, a descendência italiana, e por isso a cultura. Como elementos culturais, podemos citar os hábitos, a culinária, a música e o que perpassa todos estes contextos: a língua, variedade italiana, uma das marcas da identidade do grupo.

A comunicação humana, mais especificamente a fala, é um dos pilares das interações sociais. A língua é um bem comum e a fala um ato individual. Pensando-se que o contexto da comunidade era de indivíduos monolíngues, objetivamos apresentar os fatores conscientes e/ou inconscientes que influenciaram uma ítalo-brasileira, cuja primeira língua é uma língua de imigração italiana, que trataremos aqui como "italiano" ${ }^{\text {, }}$, a tornar-se bilíngue, e ao longo de sua vida ter o português como língua dominante, mesmo vivendo em comunidades que falassem a variedade de imigração. Através de uma entrevista, buscamos compreender os fatores sociais e/ou pessoais que a influenciaram a optar por usar predominantemente o português. O corpus para a presente pesquisa constituiu-se através de uma gravação audiovisual de uma entrevista voltada a questões (meta)linguísticas do questionário ALCF de Krug (2013). A informante é neta de italianos, gaúcha de Guaporé, que atualmente mora em Coronel Freitas-SC, cidade que foi desmembrada em 6 de outubro de 1961 de Chapecó. A seguir, aprestamos os direcionamentos metodológicos que delinearam este trabalho.

\section{Procedimentos metodológicos}

Como já exposto, o objetivo da pesquisa foi compreender motivos (in)conscientes que influenciaram uma ítalo-brasileira, cuja primeira língua era a língua de imigração italiana, a usar progressivamente, com maior dominância, o português que o italiano.

Para a coleta de dados e posterior análise do corpus selecionado que ensejaram responder a esse questionamento, realizamos uma entrevista estruturada, com parte do questionário Atlas das Línguas em Contato na Fronteira (ALCF) (KRUG, 2013).

A seção do questionário intitulado "questionário metalinguístico", utilizado para a pesquisa, é composto de perguntas sobre crenças linguísticas, que geram do entrevistado (informante) comentários sobre sua percepção e opinião em relação às línguas, aos seus usos e seus falantes.

Ao total foram 20 perguntas, sendo destas 13 objetivas 7 subjetivas, todas realizadas e respondidas em talian, ou seja; a variedade italiana de imigração falada pela informante, e por pessoas que moram na mesma cidade que ela (Coronel Freitas/SC). Para melhor compreensão do leitor:

\footnotetext{
${ }^{98}$ Para melhor contextualização, explicitamos que usamos o termo "italiano" ao nos referirmos à língua de imigração italiana falada pela informante. Não estamos caracterizando especificamente qual das variedades de italiano é a utilizada pela informante, pois não é o alvo desta pesquisa. Quando italianos chegaram ao Brasil trouxeram diferentes variedades dialetais de cada uma de suas regiões de origem, que no Brasil, através de contatos interlinguísticos e intralinguísticos assumiram características próprias. Os diferentes dialetos de italiano que chegaram ao Brasil passaram por um processo de nivelamento dialetal, surgindo entre os ítalo-descendentes uma Koiné linguística formada pela fusão dos dialetos da língua italiana em contato com o português. Neste trabalho, não descreveremos a(s) variedades de português e italiano falada pela informante, por isso, referiremo-nos a elas como "português" e "italiano".
} 
Perguntas objetivas cujas respostas eram: Italiano/Português:

1) Que língua costuma falar na família? Che lengoa ti costumi parlar ntea fameia? (KRUG, 2004; STEFFEN, 2007 apud KRUG, 2013 - questão 1)

2) Em que Língua gosta de conversar mais? Che lengoa ti piàse parlar depì? (KRUG, 2013 - questão 4)

3) Em que língua costuma falar mais? Parla depi Talian o Brasilian? (KRUG, 2013 - questão 5 adaptada)

4) Qual a sua língua materna? Qual è la prima lengo che ga imparato? (KRUG, 2013 - questão 10)

5) Quando vem visita, que língua prefere usar? Quando vien gente, che lengoa ti piàse parlar? (KRUG, 2004 apud KRUG, 2013 - questão 6)

6) Que língua fala nas seguintes ocasiões no município? Che lengoa ti parle ntele seghinte ocasion in to munissipio:

6.1) No mercado / Ntel merca

6.2) Nas lojas / Ntel lògie

6.3) No sindicado / Ntel sindicato

6.4) No restaurante / Ntel ristorante

6.5) Na prefeitura / Ntel prefeitura

6.6) No posto de saúde / Ntel posto de salute

6.7) No posto de gasolina / Ntel posto de gasolina

6.8) No trabalho / Ntel laoro

7) Quando você encontra um estranho na rua de sua cidade, em que língua você fala com ele? Quanto ti incontri una persona che non consci, che lengoa ti parli?

Perguntas objetivas, cujas respostas eram: Sim/Não:

8) Já lhe aconteceu de estar com alguém que sabia sua língua de casa, a língua italiana, mas insitia em só falar português? Ti ga catà con un persona che savea parlar talian, mas solo la volea parlar portoghese? (KRUG, 2013 - questão 9)

9) Acha importante que os filhos aprendem a língua italiana dos pais? Ti piàse che $i$ bambinni parlesse in Talian? Perchè? (KRUG 2013 - questão 28 - adaptada)

10) Há situações em que você tem vergonha de falar italiano? A le olte, ti ga vergogna di parlar talian? (KRUG, 2013 - questão 27)

11) Acha que deveria ter ensino de italiano nas escolas? La scuoladeveria insegnar parlar anca talian? (KRUG, 2013 - questão 28 adaptada)

12) Quando você fala português, mistura com italiano? Quando ti parli portoghese, mistura talian ? (KRUG, 2013 - questão 33 - adaptada)

13) Quando você fala italiano, mistura com português? Quando ti parli talian, mistura portoghese? (KRUG, 2013 - questão 34 - adaptada)

Perguntas com respostas de cunho subjetivo:

14) $O$ que acha das pessoas que só falam português, e nunca a própria língua de casa, o italiano? Che pensa dele persone che sa talian ma che solo parla portoghese? (KRUG, 2013 - questão 8)

15) Muitos jovens não falam mais a língua dos pais (italiano). O que acha disso? Tanti giòveni non parla piu Talian, Dir ge anca che? (KRUG, 2013 - questão 32)

16) Em que situações você fala a língua italiana, e em quais a português? In che posto parli talian, in che posto parli portoguese? (KRUG, 2013 - questão 26)

17) Há diferença entre o italiano falado aqui, e em outras cidades? Genè diferensa dele talian che parla qua e nantra cità? (KRUG, 2004 apud KRUG, 2013 - questão 3) 
18) Como é/foi na escola e na igreja o uso do italiano? Come si é in chiesa il talian, e in scola?

19) Como acha que as pessoas que vem de fora, veem as daqui? Cosa le persone de nantra cità le cata de noantri?

20) Como se sente mais: italiano/alemão/brasileiro? Come ti senti tu? Brasiliano(a)? Italiano(a)? (KRUG, 2004 apud KRUG, 2013 - questão 4 adaptada)

A informante é feminina, com 90 anos, e a motivação para seleção deste perfil, foi de que a geração mais velha da cidade, é a que parece usar com mais frequência o talian quando comparada às gerações mais jovens. Porém, mesmo assim, com visível esforço, optam por usar português em diversos contextos. Fato que suscitou nossa inquietação, e motivou a pesquisa.

Como exposto acima, das perguntas de cunho objetivo, em 7 delas a informante respondia se falava português ou italiano em locais públicos mencionados pelo entrevistador, e as outras 6, respondia com "sim" ou "não". As demais sete questões eram de resposta aberta, para compreendermos suas percepções acerca das línguas e seus falantes. A entrevista foi gravada com a devida autorização da participante, bem como atendendo diretrizes éticas, aprovada pelo conselho de ética em pesquisa com seres humanos (CEP) da Universidade Federal da Fronteira Sul (UFFS) sob o parecer 702.162 e no número de identificação 20380713.2.0000.5564. A entrevista durou duas horas e meia pois houve, por iniciativa da informante, comentários e fala espontânea, além das respostas às perguntas realizadas; comentários estes que também fizeram parte do corpus e foram agregados às análises.

Para realização da análise, primeiramente transcrevemos a entrevista, e depois examinamos o corpus orientados pela pergunta de pesquisa.

\section{Coronel Freitas, uma comunidade ítalo-brasileira de imigrantes oriundos do Rio Grande do} Sul

Coronel Freitas está localizada na região oeste do Estado de Santa Catarina, a 12 quilômetros de Chapecó. Possui 9.981 habitantes em uma área superficial de 233,698 km², conforme dados do Instituto Brasileiro de Geografia e Estatística (IBGE, 2019). Faz divisa ao norte com os municípios de Quilombo e União do Oeste, ao sul com Chapecó e Cordilheira Alta, ao Leste com Xaxim e Marema, e ao Oeste com Nova Itaberaba, Nova Erechim e Águas Frias.

Segundo o site oficial da cidade, o município começou a ser colonizado em 1929 por famílias de descendência italiana, procedentes do Rio Grande do Sul, na esperança de um futuro melhor. Foram atraídas pelas novas terras, grandes quantidades de erva-mate e principalmente pela possibilidade de extração de madeira que nas décadas de 1920 a 1950 eram abundantes na região.

Dentre as famílias que chegaram a Coronel Freitas (na época Chapecó) em 1946, estava nossa informante e seu esposo, que um ano após se casarem em Guaporé-RS, migraram para Coronel Freitas depois da compra de uma chácara através da empresa Colonizadora Bertaso. Assim como todos os imigrantes, vieram em busca de novas terras férteis para se estabelecerem.

\section{A (co)existência da língua de imigração italiana e o português, e fatores que motivaram a substituição da língua minoritária em detrimento da língua nacional}

A informante que participou desta pesquisa nasceu em 1924 em Guaporé-RS. Mudou-se para Santa Catarina, (na época município de Chapecó) em 1946, um ano após casar-se. Neta de imigrantes, em sua infância, a única língua que compreendia e utilizava era o italiano. Quando fez referência a seu avô, contou que:

L' era cego, no? Lu parlea italian, dava catecismo, par tutti i tozatei. I là lora lu parlea italian, el dizea que la em Italia diz que laurea... si laurea so sei mesi que era caldo 
dopo no si laurea. Lora era lá cerrati sui se escaldea em casa. Il nonno contava que era tré mesi par vegner dell' italia per Brasil, de vapor. Quà tel Brasil era molto méglio. Una città più bella...le ghà piazesto tanto quà tel Brasil... Non parlea brazilian, tutto italian. (Informação verbal). ${ }^{99}$

Cresceu junto a seus avós e pais, na cidade de Guaporé-RS. A colônia de Guaporé foi criada em 1892, em terras pertencentes aos municípios de Lajeado e Passo Fundo. Os primeiros imigrantes provindos das colônias de Caxias do Sul, Bento Gonçalves e Veranópolis chegaram ao local, de modo que, em 1896, a colônia já contava com cerca de 7 mil habitantes, em sua maioria italianos, incluindo alguns alemães, poloneses, russos e austríacos.

A informante não se recorda de contatos com falantes de outras línguas que não fosse a variedade italiana. Era a única língua que compreendia e que utilizava na comunidade. A informante reporta que onde morava, na cidade de Guaporé, esta língua estava em todos os espaços: em casa, na vizinhança, no comércio e na igreja. Ela relata que:

Non parlea brazilian, tutto italian. Quando precisava de alguma coisa, ia te la bodega. el primero tempo tutto italian, dópo ghà muda. Lora se dicea: Mi so venhesta quá comprar um quilo de açucro. Son vignesta quà comprar um quilo de erba-mate. son vignesta quà compra um quilo de sal. Son vignesta quà compra chiodi. Coisa que precisava, né? La mama la me ghà mandá compra due metri di roba ma de quella più populare que ghè esiste..

I na igreja onde rezava a missa no? là o padre el padre là parlea italian, enton todo mundo là ia assisti a missa. El padre rezava a missa tutto italiana, i lora, intanto que el prete rezea la messa i noantri se rezea el terço. (Informação verbal). ${ }^{100}$

Fishman (2006) ao apresentar exemplos de manutenção linguística aponta fatores que influenciam no processo de manutenção de uma língua, são eles: a) fator demográfico (quantidade de falantes de determinada língua); b) geográfico (se refere ao tamanho e localização mais isolada da comunidade de fala); c) econômico (caso em que a comunidade é auto-sustentável ou não); d) cultural (quando a língua identifica o grupo); e) regulamentação (existência de leis que estimulem e valorizem o uso de uma determinada língua). No contexto da informante, apresentava-se de forma marcante os fatores: demográfico, geográfico e econômico, pois era uma localidade de pequenos agricultores, de subsistência, oriundos da Itália. O quinto fator apontado por Fishman (2006), ou seja; o de regulamentação operou contrariamente à manutenção e incentivo da língua, observando assim, as forças externas e internas que atuam na diminuição do uso de uma variedade. Fatores que acompanharemos, mais detalhadamente no decorrer deste artigo.

A informante recorda-se claramente do período que foi o "divisor de águas": o momento em que sentiu que precisaria impreterivelmente aprender a falar o "brasilian". Ela lembra-se que era uma jovem de quinze anos de idade.

\footnotetext{
${ }^{99}$ Ele era cego. Falava italiano, dava catecismo para todas as crianças. E lá, então, falava tudo em italiano, ele dizia que lá na Itália diz que se trabalhava só seis meses que era quente e depois não se trabalhava. Então, se fechava em casa para se esquentar. O nono contava que levava três meses para vir da Itália para o Brasil, de vapor. Que aqui no Brasil era muito melhor. Uma cidade mais bonita... Ele gostou muito daqui do Brasil, não falava português, tudo em Italiano.

${ }^{100}$ Não se falava português, tudo italiano. Quando precisava de alguma coisa, ia lá na bodega. No primeiro tempo era tudo em italiano, depois mudou. Então se dizia: Vim aqui para comprar um quilo de açúcar. Vim aqui para comprar um quilo de erva-mate. Vim aqui para comprar um quilo de sal. Vim aqui para comprar prego. Coisas que precisavam, né? A mãe me mandou aqui para comprar dois metros de tecido, mas aquele mais comum, barato que tem... E na igreja onde rezava a missa? Lá o padre falava Italiano, então todo mundo lá ia assistir a missa. O padre rezava a missa toda em Italiano, e então, enquanto que o padre rezava a missa, nós rezávamos o terço.
} 
Até os quinze ano, tutto, tutto en italian, dopo mudo, começo a vim eleiçon tudo mudo, tudo começo a aprende. El primo tempo que ghá escomicià parlar brazilian, è stato la guerra, non só, mi non só qui anni non mi intendo. Enton lori ghà escomicia prender le giente que parlea italian, no? I era so brigue, brigue, brigue...Pegava mulher, botava na cadeia...Enton depois começo a sair giente que começo a falar português... Enton começaram a aprender. Tutti si espaurea porque andarne dove desso? Toca estar casa. Se ia mesmo que se precisava, se no se ficava em casa. Dopo con la guerra se escumicio a falar mais português. (Informação verbal). ${ }^{101}$

Era o ano de 1939, momento histórico conturbado tanto no cenário nacional quanto internacional. No âmbito nacional, em 1938, segundo Chaves (2003), iniciou-se oficialmente o Estado Novo do governo Getúlio Vargas, misturando valores nacionalistas e autoritários, iniciando a "grande obra nacionalizadora", apoiando-se num conjunto de leis que tinham como objetivo suprimir toda e qualquer atividade política de estrangeiros no Brasil e a "adaptação ao meio nacional dos brasileiros descendentes de estrangeiros". O programa de ação dessa campanha de nacionalização tinha como principal objetivo erradicar as influências estrangeiras atuantes, sobretudo, nos estados do sul, e incutir nas populações de origem europeia, principalmente os alemães, poloneses e italianos, o sentimento de brasilidade. As medidas que fizeram parte deste plano incluíam: nacionalização do ensino, com a obrigatoriedade do ensino e português nas escolas, proibição de falar línguas estrangeiras em público, e censura a programas de rádio e restrições à imprensa em língua estrangeira.

No âmbito internacional, era o final do período entre guerras e início da Segunda Guerra Mundial. Este panorama de repressão intensificou-se em 1942 com a entrada do Brasil no conflito. Nesse período, as grandes potências mundiais entraram em confronto na Segunda Guerra, quando observamos a cisão entre os países totalitários (Alemanha, Japão e Itália) e as nações democráticas (Estados Unidos, França e Inglaterra). Ao longo do conflito, cada um desses grupos em confronto buscou apoio político-militar de outras nações aliadas. Getúlio Vargas declarou guerra contra os italianos e alemães em agosto de 1942. Esta decisão intensificou o panorama de repressão às nacionalidades ligadas às potências do Eixo: alemães, italianos e japoneses (Oliveira 1996).

Segundo Laps (2003), o projeto nacionalista do Estado Novo, que pretendia realizar a "formação da identidade brasileira", tinha como objetivo a integração dos núcleos de imigrantes na cultura nacional. Falar, cantar ou escutar canções alemãs, possuir/ouvir um rádio, sendo alemão, italiano ou japonês, tudo isto estava proibido. O governo tentava dar fim a qualquer impulso de formação de um Estado paralelo no sul do país. Moser (2004) afirma que os colonos eram perseguidos na chamada "nacionalização forçada", pelo fato de não terem se integrado nacionalmente através do conhecimento e uso da língua oficial. Estereotipados como "inimigos da Pátria”, eram denominados de "fascistas" e "nazistas" e como tais, humilhados, presos, extorquidos monetariamente e castigados, a pretexto de terem, às vezes, pronunciado uma só palavra em língua estrangeira.

Os "brigue" mencionados pela informante eram, segundo ela e outros membros da comunidade de mesma faixa etária, delatores recrutados às vezes entre os membros da própria etnia. Não se respeitava nem o espaço privado. A proibição de expressar a identidade italiana foi reforçada por um aparelho policial extremamente feroz. As delações passaram a ocorrer sistematicamente, e as relações passaram a ser de tensões e medo de ser delatado (MOSER, 2004).

\footnotetext{
${ }^{101}$ Até os quinze anos, se falava tudo, tudo em italiano. Depois, mudou, começou a vir eleição, tudo mudou, todos começaram a aprender. No primeiro momento que se começou a falar português, foi quando começou a guerra, não sei, não sei que ano, não lembro. Então, começaram a prender pessoas que falasse, italiano, né? E eram "brigue", "brigue"... pegavam mulheres, botavam na cadeia... Então depois começou a sair pessoas que falavam o português... Então começaram a aprender. Todos tinham medo, porque andar aonde, agora? Vamos ter que ficar em casa. Saía mesmo se precisava, se não, se ficava em casa. Depois, com a guerra, se começou a falar mais o português.
} 
Neste contexto de conflito, de opressão e medo, a informante sentiu que precisava aprender o português, e, aos poucos, pessoas que sabiam falar a língua começaram a chegar à comunidade com o intuito de colaborar com a aprendizagem do português. Reuniam-se então na igreja e ensinavam aos falantes da variedade italiana o português:

Dopo ghà escumicia vegner gente que parlea, que expliquea, tinha reunion [...] explicava, no? tale palavra é assim assim, enton todo mundo começo a ter prática, i aprende, no? fazia tanto te le chiese, [...] assistia la missa, dopo ficava, la explicava tal palavra é assim, assim... No começo era tutto atrapaiado, oh... dava cada atrapaiason! Começava a falar uma coisa e quando era por fim não saia nada... foi pesado pra começa a aprende. Ainda agora do umas atrapaiada, tem palavra que num con consigo fala direito. [...] agora que tenho prática me sinto melhor fala em português. (Informação verbal). ${ }^{102}$

O processo de aprendizagem das línguas, pela informante, ocorreu de forma consecutiva/sucessiva que, de acordo com Romaine (1995, p. 181) é quando o indivíduo aprende uma língua, depois a outra. A informante não era alfabetizada, pois não teve a oportunidade de frequentar escola e, então, o processo de ensino-aprendizagem era exclusivamente através da oralidade. A nova língua aprendida era usada em contextos sociais que o demandassem, pois em casa e, quando possível, dentro da comunidade, continuava-se a usar a variedade italiana. A primeira mola propulsora para o uso do português foi a repressão e punição, como já apresentado, e o segundo fator, além do medo, foi o receio de ser mal compreendida, e acidentalmente ofender aos que não conheciam a variedade italiana, conforme observamos no relato a seguir:

Acontecesto tante volta de que venia quá giente que parlea brazilian i eu no capia niente. A volte ofendea anca porque no era bona de capir cosa que dizia, no? (Informação verbal). ${ }^{103}$

A informante explicou que não se sentia à vontade e segura de estar se comunicando bem em todos os contextos de sua convivência por não entender o português, mas também por achar o italiano uma forma mais "bruta" de se expressar, que com o português sentia que poderia se expressar melhor, de maneira bonita, e principalmente sem ofensas.

Assim, é possível observar que a comunidade local em que a informante morava configuravase como uma sociedade de indivíduos monolíngues, e, devido aos fatores expostos, iniciou-se um processo de reconfiguração, uma sociedade que caminhava para uma realidade de diglossia com bilinguismo. Optou pelo português nas esferas sociais, por dois motivos: "paura" (medo) de repressão, e receio de provocar ofensas, enquanto que em família e amigos de confiança permanecia o uso do italiano.

Fishman (2006, p. 29) apresenta a ideia de diglossia como a realidade de uma comunidade linguística em que as pessoas utilizam duas ou mais línguas para a comunicação interna (intrasociety). Ferguson (1974, p. 111) complementa a definição:

\footnotetext{
${ }^{102}$ Depois começou a vir pessoas que falavam (português), que explicavam, tinha reunião [...] Explicavam, né? Tal palavra é assim, assim assim, então todo mundo começou a ter prática e aprender, né? Se fazia isso tanto na igreja [...] se assitia a missa, depois ficava lá, explicavam, tal palavra é assim... No começo era tudo atrapalhado, ah... dava cada atrapalhação! Começava a falar uma coisa e quando era por fim não saia nada... foi pesado para começar a aprender. Ainda agora faço umas atrapalhadas, tem palavras que não consigo falar direito [...] agora que tenho prática me sinto melhor falar em português.

${ }^{103}$ Aconteceu tantas vezes que vinham pessoas que falavam português e eu não entendia nada. Às vezes até ofendia porque não era capaz de entender o que diziam, né?
} 
Fatores (in)conscientes que influenciaram uma ítalo-brasileira a usar progressivamente o português em detrimento da variedade italiana | 203

É uma situação linguística relativamente estável na qual além dos dialetos principais da língua (que podem incluir um padrão ou padrões regionais) há uma variedade superposta, muito divergente, altamente codificada (na maioria das vezes gramaticalmente mais complexa), veículo de um grande e respeitável corpo de literatura escrita, que é aprendida principalmente através da educação formal e usada na maior parte da escrita e fala formais, mas que não é usada em nenhum setor da comunidade na conversação usual.

Segundo Ferguson (1974, p. 100) a diglossia pode se desenvolver a partir de várias origens e ocorrer em diferentes situações linguísticas, como: Função, Prestígio, Herança Literária, Aquisição, Padronização, Estabilidade, Gramática, Léxico.

Em contextos diglóssicos uma das situações que impulsionam o uso concomitante de mais de uma língua é a função que uma língua exerce em detrimento da outra, ou seja; em um conjunto de situações somente uma língua é apropriada, e, em outros contextos, a outra. O Prestígio, é quando as pessoas consideram uma língua superior em vários aspectos. A Herança Literária é o acervo considerável de literatura escrita em uma língua altamente considerada pela comunidade linguística. A Aquisição é o contexto em que a língua usada na comunicação dos pais com as crianças, é diferente daquela utilizada no contexto educacional. A Padronização é uma norma estabelecida para pronúncia, gramática, vocabulário, que permite variação apenas dentro de certos limites, as línguas que são superpostas na sociedade são aquelas nas quais há uma forte tradição de estudo, enquanto estudos descritivos e normativos são reduzidos ou inexistentes nas variedades consideradas de menor prestígio. A Estabilidade concerne à reflexão de que se poderia supor que a diglossia fosse altamente instável, com tendências a se transformar em uma situação linguística mais estável. Porém ela persiste a alguns séculos e a evidência de alguns casos parece mostrar que ela pode perdurar ainda por mais muitos anos. A gramática, são as diferenças estruturais entre as línguas da comunidade. No que se refere ao léxico, as línguas e/ou variedades usadas pela comunidade podem utilizar o mesmo vocabulário, com variações na forma e com diferenças de uso e significado.

Dentre estas situações de diglossia apresentadas por Ferguson (1974), no caso que estamos analisando, o fator prestígio foi uma forte característica e a mola propulsora para o aprendizado da língua oficial do país, somado ao fato de que como uma língua "formal" poderia ser usado sem riscos de punição e/ou ofensas.

Ao sair da casa dos pais ao casar-se, a informante relata que continuou a usar predominantemente a variedade italiana com seu esposo e filhos, e que esta escolha não foi uma decisão consciente, que não demandou esforço ou disciplina, foi natural. A função do uso do português continuava sendo em contextos externos, na comunidade, ao se comunicar com pessoas que trabalhavam no comércio e até igreja (neste momento as missas já eram ministradas em português). Quando questionada sobre as motivações de usar a variedade de imigração italiana no contexto familiar, a informante explica que era assim que melhor se sentia ao comunicar-se com o esposo, filhos e também com amigos, por mais que estes falassem o português, era na variedade italiana que preferia conversar. Fora destes círculos, o familiar e de amigos, por mais que o interlocutor soubesse a variedade, a informante ressalta que a abordagem da conversa sempre era iniciada em português.

É interessante observar que, nos contatos afetivos, inconscientemente a língua dominante era a língua materna da informante. A língua em que primeiro se comunicou com os pais e avós e posteriormente a língua que elegeu para comunicar-se com os filhos. Segundo Altenhofen (2004, p. 151): 
Estabelece-se via de regra uma relação de identidade entre língua materna e família, tão forte como o vínculo que une mãe-pai e filho. Essa identidade afetiva é proporcional ao estilo de interação dos pais com as crianças e parece aumentar na medida em que a língua usada na família se distingue da língua do meio, como nos casos dos falantes de línguas minoritárias.

Quando os filhos começaram a frequentar a escola, tiveram o primeiro contato intenso com o português, pois fora do contexto escolar não havia acesso a rádio e televisão para o contato com a língua, e os vizinhos da comunidade em que viviam falavam também a variedade italiana.

O contexto educacional da época exigia que as crianças falassem apenas o português em sala de aula, e, se não o fizessem, estavam suscetíveis à punição. Com a preocupação de apoiá-los e de que não sofressem com esta realidade, a informante buscou aprimorar seu próprio conhecimento em português com os filhos, aprendendo também com eles o português e incentivando-os a falar esta língua em casa.

Com o passar do tempo, a chegada da eletricidade e de mídias de comunicação como o rádio, o jornal e posteriormente a televisão, oportunizou-se o acesso e o contato com o português e consequentemente um maior desenvolvimento de sua compreensão.

Até então, as motivações para o uso do português foram o medo de punição ao falar a variedade italiana, o receio de ofender as pessoas ao comunicar-se na língua minoritária e a preocupação com a qualidade da educação dos filhos. Com a chegada dos netos, uma vez mais sentiu que precisaria lapidar suas habilidades com o português para estreitar os vínculos afetivos. A preocupação agora não era mais conseguir entendê-los (todos falavam apenas o português), pois os compreendia muito bem, a necessidade agora focava-se na expansão do conhecimento e uso lexical do português para melhor comunicar-se com eles.

Em um relato, a informante lembra que uma de suas netas pediu à avó que fizesse sopa de galinha, e ela respondeu que sim, que iria fazer "sopa de guli". A neta foi então pedir para a mãe fazer sopa porque a avó não iria fazer o que ela teria solicitado. Mas era exatamente a mesma comida a que as duas estavam se referindo. A informante usava a estrutura do português, mas em sua comunicação havia um mixing ${ }^{104}$ de léxico do italiano na estrutura, o que a fazia sentir-se distanciada dos netos em termos de comunicação.

Uma segunda preocupação que levou a informante por decidir não usar e também não incentivar a família ao ensino de duas línguas simultaneamente para as crianças, no caso os netos, é acreditar que a aprendizagem seja difícil e de alguma forma prejudique a criança:

Acho que seria bonito aprende fala italiano, no? mas quando pequeno non, porque é muito confuso, eles se atrapalham bastante. Depois de grandinho, depois que fala bem o português sim, mas antes non, porque se atrapalham. (Informação verbal).

Esta concepção de "atrapalhar-se" com as duas línguas provém do fato de que, quando duas línguas distintas estão sendo aprendidas, ocorre a mistura de ambas na comunicação, denominado de "mixed code", que é definido como "a way of speaking which shows evidence of substantial amounts of morpho-syntactic and/or lexical material from at least two different languages" (MUYSKEN, 2007, p. 315). ${ }^{105}$ Este processo é possível que aconteça e é natural. Não significa que a criança esteja confusa, e sim que está em processo de aprendizagem e desenvolvimento de sua linguagem, pois "learning to speak more than one language often involves putting together material from two languages, this is

\footnotetext{
${ }^{104}$ Code mixing é a mudança de código intrassentencial, quando a mudança de uma língua para outra acontece dentro da mesma sentença (THOMASON, 2001, p. 132).

${ }^{105}$ Uma maneira de falar que apresenta elementos morfo-sintáticos e/ou lexicais de pelo menos duas línguas diferentes (MUYSKEN, 2007, p. 315).
} 
a part of the normal process of growing up bilingualy and acquiring competence in more than one language" (ROMAINE, 1995, p. 2). ${ }^{106}$

Esta mistura é uma preocupação comum a muitos pais, que, receosos de que isso possa repercutir negativamente nas capacidades cognitivas e no desenvolvimento da comunicação das crianças, decidem por não criarem filhos bilíngues. Quando uma segunda língua não for vista como uma língua hegemônica, como ferramenta de ascensão social, a decisão de criar filhos monolíngues é a que normalmente prevalece. Edwards e Newcombe (2006, p. 149) reforçam que:

Because myths about bilingualism are so prevalent, parents are often plagued with doubt (Boodz 1994). They may mistakenly believe that early exposure to two languages will result in confusion, they may also worry about what will happen when their child arrives in school with little or no knowledge of the language. When the minority language is in competition, the decision to use another language in the home is particularly difficult. Minority languages can seem old-fashioned and unglamorous $[\ldots]^{107}$

Muito maior que esta preocupação em prejudicar os netos com a mistura de duas línguas, estava a preocupação em construir vínculos afetivos com eles, e a ideia de que o uso de uma outra língua causasse estranhamento e um distanciamento foi a nova mola propulsora para o uso mais frequente do português em um espaço em que antes prevalecia a variedade italiana por décadas: o contexto familiar.

O movimento de imigração primeiramente foi de espaço geográfico, com a colonização, e depois dentro do campo linguístico. A língua majoritária migrava do convívio externo para o interno, a língua afetiva que até então era sua língua materna, ou seja, a variedade italiana, não exercia esta função nos momentos de afetividade com os netos; as duas línguas se construíam em suas funções e espaços na vida da informante.

É interessante refletir como este movimento e o bilinguismo influenciam na construção da identidade. Pois quando questionada se a informante sentia-se brasileira ou italiana, sua resposta foi: (informação verbal)

Oh, mi era italiana, no? ma adesso so ntel brazil, me digo que saró una braziliana. ${ }^{108}$

A informante, que nunca esteve na Itália, quando as relações de convívio eram prioritariamente com a variedade italiana, sentia-se italiana. A partir do momento em que passaram a ser primordialmente em português, sente-se brasileira.

Ao longo da entrevista, apresentamos motivações da informante em decidir por usar predominante o português. As perguntas eram conduzidas em talian, e as respostas eram parte na variedade italiana, e parte em português. Ao iniciarmos a entrevista, a informante questionou se era preciso responder em italiano ou poderia ser em português. Orientamos que poderia falar como preferisse, como sentia-se à vontade. Respondeu então que estava sem prática, mas que, mesmo assim, iria tentar falar na variedade italiana.

\footnotetext{
${ }^{106}$ Aprender a falar mais de uma língua frequentemente envolve misturar material de duas línguas, isto é uma parte natural do processo de quando somos criados de forma bilíngue, e adquirimos competência em mais de uma língua (ROMAINE, 1995, p. 2).

${ }^{107}$ Porque mitos sobre bilinguismo são prevalentes, pais frequentemente se deparam com a dúvida (Boodz, 1994). Eles podem erroneamente acreditar que a exposição precoce a duas línguas resultará em confusão, eles podem também se preocuparem sobre o que acontecerá quando seus filhos chegarão à escola com pouco ou nenhum conhecimento da língua. Quando a língua minoritária está em competição, a decisão por usar uma outra língua em casa é particularmente difícil. Línguas minoritárias podem parecer antiquadas, e menos glamurosas [...]

${ }^{108}$ Eu era italiana, né? Mas agora estou no Brasil, digo que sou brasileira.
} 
Neste transitar entre as duas línguas durante a entrevista, as narrações de eventos que ocorreram na sua infância e juventude apresentavam ter mais elementos da variedade italiana, e em descrições de fatos mais recentes de sua vida apresentavam mais elementos do português. Por vários momentos, ao responder as perguntas na variedade italiana ao pesquisador, sem ser solicitada, traduzia para o português o que havia acabado de dizer, com a preocupação de que o interlocutor não estivesse compreendendo o que dizia, por mais que este lhe tenha explicado que, por mais que não falasse a variedade, a compreendia. Através desta observação, e do relato do pedido da sopa pela neta, vemos que é presente na informante a concepção de que a comunicação efetiva dar-se-á quando a mesma for toda em uma única língua, sem alterná-lo. Fator este que também a motivou a migrar para o uso mais dominante de uma língua, tentando não alterná-lo e assim influenciar seus filhos e netos para o mesmo direcionamento.

Fishman (2006, p. 407) realizou uma pesquisa nos Estados Unidos com famílias descendentes de imigrantes e detectou que são poucos os falantes de línguas minoritárias que sejam mais do que duas gerações em relação a geração dos imigrantes que chegaram ao país. Esta questão remete a três aspectos deste contexto linguístico: Primeiro, que os netos e bisnetos têm se tornado monolíngues em português. ${ }^{109}$ Segundo, permaneceram poucos falantes da língua minoritária. Terceiro, nem viagens, trabalho ou o contexto educacional oportunizam condições de promoção do uso da língua minoritária.

Os resultados desta pesquisa de Fishman trazem um elemento bastante característico à realidade linguística da informante: A terceira geração não é mais falante da variedade italiana, e os meios de convivência social, como escola, não promoviam o uso da língua minoritária. O cenário das experiências foi de um bilinguismo com uma certa "competição" entre a primeira língua e a segunda língua. É como se "The languages remain exposed to then Darwinian law of the linguistic jungle: the strong will survive, and in competition with the strong, the weak die off" (FISHMAN, 2006, p. 421). ${ }^{110}$ Para a informante, para primeiramente "sobreviver" às opressões que sofriam os que não falassem a língua oficial do país, e depois sentir-se integrada, aceita e pertencente à sociedade e posteriormente pelos netos, e oportunizar à família possibilidades de ascensão econômico-sociais através do progresso e sucesso com os estudos, sua primeira língua, a variedade de imigração italiana, que no início era a mais forte, foi aos poucos perdendo parte de sua força e dividindo espaço com o português, que continuou gradativamente abrangendo mais espaços e funções, permeando todas suas relações sociais e familiares.

\section{Considerações finais}

O objetivo do trabalho foi investigar os fatores (in)conscientes que impulsionaram o uso gradual e cada vez mais frequente do português em detrimento da variedade italiana por uma ítalobrasileira, gaúcha, hoje com 90 anos e residente no município de Coronel Freitas, oeste de Santa Catarina. Este município foi colonizado, em toda sua extensão, por descendentes de italianos, que no início, tinham como prevalente o uso da variedade italiana e hoje o uso do português.

Este processo de transição e de convívio entre as duas línguas teve diferentes configurações ao longo da vida da informante. Até os quinze anos de idade era monolíngue, e a partir de então diferentes fatores a impulsionaram a usar o português, primeiramente apenas em situações isoladas, em contextos sociais, e depois em casa, no convívio familiar.

A primeira mola propulsora que a "forçou" à aprendizagem do português foi aos quinze anos de idade, em 1939, com a política nacional denominada de "Estado Novo" que impunha valores nacionalistas em um conjunto de ações que tinham como objetivo suprimir toda e qualquer política de estrangeiros no Brasil. As medidas que fizeram parte deste plano incluíam:

\footnotetext{
${ }^{109}$ Porém vale destacar que eles podem ter se tornado bilíngues na escola, de línguas prestigiadas.

${ }^{110}$ As línguas permanecem expostas à lei Darwiniana da selva linguística: as fortes sobreviverão, e em competição com as fortes, as fracas desaparecerão.
} 
Nacionalização do ensino, com a obrigatoriedade do ensino e português nas escolas, proibição de falar línguas estrangeiras em público, e censura a programas de rádio e restrições à imprensa em língua estrangeira. Dentro deste contexto de punição, além deste receio, a preocupação era em ofender os que não conhecessem a variedade de imigração italiana com o seu uso.

$\mathrm{Na}$ década de cinquenta, com a frequência dos filhos no contexto escolar que impunha medidas que coibiam o uso da variedade italiana, e preocupada com o bom desenvolvimento educacional dos filhos, buscou aprimorar suas habilidades com português e incentivá-los a isso também, iniciando o uso do português em casa, junto à variedade italiana.

A partir da década de 70, com o nascimento dos netos que não aprenderam a língua minoritária com os seus pais, a informante, com o intuito de construir e estreitar vínculos afetivos com eles, assumiu a postura de, no contexto familiar, intensificar e gradualmente usar dominantemente a língua nacional.

Permeando estes contextos que impulsionaram o uso mais frequente da nova língua estavam o medo, o interesse de construir amizades e relações com pessoas não-falantes da variedade, a preocupação com a educação dos filhos, pensando que o uso concomitante das duas línguas pudesse prejudicá-los em seu progresso educacional. Esta mesma preocupação teve com os netos, somado também ao fato de buscar uma maior aproximação e maiores vínculos afetivos através do uso da língua materna deles, que é o português.

A pergunta que norteou a pesquisa (compreender fatores (in)conscientes que influenciaram uma ítalo-brasileira a usar progressivamente, com maior dominância, o português que o italiano) foi respondida. Inicialmente optamos por usar o termo (inconsciente) por não estarmos certos ser foram iniciativas tomadas com total ciência por parte da informante ou não. Ao longo do trabalho percebemos que foram decisões conscientes, tomadas em diferentes circunstâncias e fases da vida.

Os dados mostraram que fatores externos à vida familiar, como político-ideológicos, educacionais socioeconômicos e culturais abriram as portas do seio familiar para a (co)existência de uma nova língua, que ao longo do tempo e das gerações foi fortalecendo-se cada vez mais.

Horst e Krug (2012) desenvolveram uma pesquisa motivados a compreender fatores de redução na aplicação de variedades alemãs (Hunsrückisch, Westfälisch e Hochdeutsch) em troca do português, especialmente nos centros urbanos e entre as gerações mais novas na pesquisa. Constatou-se, através do estudo que o processo de lusitanização de termos de Alemão está diretamente relacionado a casamentos interétnicos. Trazendo, assim mais um elemento a complementar os fatores apontados por Fishman (2006).

O tecido linguístico de uma nação é entrelaçado de muitos fios, que sofrem forças intralinguísticas e principalmente inter e extralinguísticas. Compreender estes elementos contribuem na desconstrução de preconceitos e favorecem uma melhor direção ao trabalho em prol da manutenção da diversidade linguística de uma região. Grande e fértil é o solo brasileiro nesta temática.

\section{Referências}

ALTENHOFEN, C.V. Migrações e Contatos Linguísticos na perspectiva da geolinguística pluridimensional contatual. Revista de Letras@mentos - Revista de Estudos Linguísticos e Literários, 12. ed., 2. sem. 2013.

ALTENHOFEN, C.V.; MARGOTTI, F. W. O português de contato e o contato com as línguas de imigração no Brasil. In: MELlO, H.; ALTENHOFEN, C.V.; RASO, T. (Orgs.). Os Contatos Linguísticos no Brasil. Belo Horizonte: UFMG, 2011. pp. 289-315.

ALTENHOFEN, C.V. O conceito de língua materna e suas implicações para o bilingüismo (em alemão e português). Martius-Staden-Jahrbuch, São Paulo, n. 51, pp. 135-165, 2004. 
208 | Cristiane Horst, Marcelo Jacó Krug, Simone Raquel Bernieri

BHATIA, T.K.; RITCHIE, W.C. (Eds.). The handbook of bilingualism. Malden, Oxford: Blackwell Publishing, 2006. pp. 406-436.

CHAVES, P. A. C. O exército e a campanha de nacionalização do Estado Novo. 2003. Monografia (Graduação em História) - Universidade Federal do Paraná, Curitiba, 2003.

CORONEL FREITAS. Disponível em: <www.coronelfreitas.sc.gov.br> Acesso em novembro 2015. EDWARDS, V; NEWCOMBE, L.P. Back to basics: marketing the benefits of bilingualism to parents Published. In: GARCÍA, O.; SKUTNABB-KANGAS, T.; TORRES-GUZMÁN, M.E. (Eds.). Imagining Multilingual Schools: Languages in Education and Glocalization. Bristol: Multilingual Matters, 2006.

FERGUSON, C.A. Diglossia. In: FONSECA, S.V.; NEVES, M.F. (Orgs.). Sociolinguística. Rio de Janeiro: Eldorado, 1974 [1959]. pp. 99-118.

FERRAZ, A.P. O panorama linguístico brasileiro: a coexistência de línguas minoritárias com o português. Filologia Linguística Portuguesa, n. 9, pp. 43-73, 2007.

FISHMAN, J.A. Language maintenance, language shift, and reversing language shift. In: BHATIA, T.K.; RITCHIE, W.C. (Eds.). The Handbook of bilingualism. Malden, Oxford: Blackwell Publishing, 2006. pp. 406-436.

FISHMAN, J. Language maintenance, language shift, and reversing language shift. In: FISHMAN, J.A. Bilingualism with and without diglossia; diglossia with and without bilingualism. Journal of Social Issues, v. 23, n. 2, pp. 29-38, 1977.

HORST, C.; KRUG, M. Línguas em contato no sul do Brasil: um estudo de caso do português e da variedade alemã Hunsrückisch. PAPIA: Revista Brasileira de Estudos do Contato Linguístico, São Paulo, v. 22, n. 2, 2012.

IBGE. Cidades. Disponível em: <http://www.cidades.ibge.gov.br>. Acesso em: 29 set. 2019.

KRUG, M.J. ALCF: Missões Misiones Atlas das linguas em contato na fronteira. Questionário pluridimensional do Atlas das línguas em contato na fronteira Missões no Brasil, Misiones na Argentina. 2013.

KRUG, M.J. Questionário do Atlas das Linguas em Contato na Fronteira. No prelo.

LAPS, L. Alemães em Santa Catarina: da história não escrita à necessidade da História. Jul. 2003. Disponível em: <http://www.anovademocracia.com.br>. Acesso em: 2 jan. 2015.

MOSER, A. A violência do estado novo brasileiro contra os colonos descendentes de imigrantes italianos em Santa Catarina durante a Segunda Guerra Mundial. 2004. Disponível em: <http://www.ipol.org.br/ler.php?cod=200>. Acesso em: 3 jan. 2015.

MUYSKEN, P. Mixed Codes. In: AUER, P.; WIE, L. (Eds.). Handbook of multilingualism and multilingual communication. Berlin, New York: Mouton de Gruyter, 2007. pp. 315-330.

OLIVEIRA, G.M. Plurilinguismo no Brasil. Brasília: IPOL, 2008.

OLIVEIRA, S. Getúlio Vargas depoe: O Brasil na segunda guerra mundial. Revisão: 2006.

ROMAINE, S. Introduction to the Study of Bilingualism. In: ROMAINE, Suzanne. Bilingualism. 2. ed. Oxford: Brazil Blackwll, 1995 [1989]. pp. 1-22.

ROMAINE, S. The bilingual child. In: ROMAINE, Suzanne. Bilingualism. 2. d. Oxford: Brazil Blackwell, 1995 [1989]. pp. 181-241.

THOMASON, S.G. Language Contact. Edinburgh: Edinburgh University Press, 2001.

VICENZI, R. Mito e história na colonização do oeste catarinense. Chapecó, SC: Argos, 2008.

Recebido em: 10/10/19

Aceito em: 07/11/19 